Research Article

\title{
Level Detection Equipment for Measuring the Influence of Different Leveling Accuracies on Linear Error
}

\author{
Shao-Hsien Chen ${ }^{1}{ }^{1}$ and Chi-Li Ji ${ }^{2}$ \\ ${ }^{1}$ The Graduate Institute of Precision Manufacturing, National Chin-Yi University of Technology, No. 57, Sec. 2, Zhongshan Rd., \\ Taiping Dist., Taichung 41170, Taiwan \\ ${ }^{2}$ Department of Mechanical Engineering, National Chin-Yi University of Technology, No. 57, Sec. 2, Zhongshan Rd., Taiping Dist., \\ Taichung 41170, Taiwan
}

Correspondence should be addressed to Shao-Hsien Chen; e6036@ncut.edu.tw

Received 10 February 2021; Revised 28 July 2021; Accepted 18 August 2021; Published 6 September 2021

Academic Editor: Li Shuai

Copyright (C) 2021 Shao-Hsien Chen and Chi-Li Ji. This is an open access article distributed under the Creative Commons Attribution License, which permits unrestricted use, distribution, and reproduction in any medium, provided the original work is properly cited.

\begin{abstract}
This study developed a level detection equipment which is used in computer numerical control (CNC) machine tool to determine the impact of leveling accuracy on rectilinear motion accuracy. When the CNC precision machine tool has accuracy deterioration under external load or internal stress, mainly caused error is leveling error, this research and development equipment can immediate to analyze and measurement. The allowable error of leveling accuracy can be obtained after experimental validation. The kinematic error relatively increases with leveling error. When the leveling accuracy is within the allowable error, the kinematic error relatively decreases. The main kinematic error items measured in this study include EXX, EBY, EAX, and EYY. The level detection equipment is developed in this study, and the fuzzy regression analysis is used for modeling. The model that has high accuracy in the test of the $X$-axis is $R^{2}=0.9764$ and $P=0.0506$, and $Y$-axis is $R^{2}=$ 0.9756 and $P=0.0524$. In terms of filtering, Kalman filtering is used for signal processing, the measured values and $X$-axis and $Y$-axis after filtering are improved by $94.1 \%$ and $86.2 \%$, respectively, the repeatability of this system is about A grade capability of precision (Cp), resolution is $\pm 0.0001^{\circ}$, and the stability is at least B grade capability of accuracy (Ca). This equipment has the advantages of low cost, high precision, and 2-axis measurement. This machine tool which has the straightness increases with $X$ and $Y$ axes' leveling accuracy errors, when the $X / Y$ leveling accuracy is within $\pm 0.01 \mathrm{~mm} / \mathrm{m}$, and there is the best straightness and conforms to the ISO230 standard (Lee et al., 2020).
\end{abstract}

\section{Introduction}

The geometric error measurement is the most important accuracy detection part of the machine tool manufacturing process. In order to increase the machine tool accuracy, the geometric errors of various axes must be reduced, and the error range must be in the international tolerance range. The precision instrument is used for inspection in the assembly of machine tool and adjusting or compensating the errors in the machining process. The geometric error detection methods for machine tools include the direct measurement method and indirect measurement method. Nowadays, on the industry application, there is not used of electrolytic tilt sensor in the leveling accuracy measurement and monitoring system of CNC machine tools. This research which used electrolytic tilt sensor has been high accuracy, resolution, and repeatability that used fuzzy regression analysis modeling for model building and Kalman filtering for signal processing, and it can be connected with CNC- and PC-based controller.

Relative measurement instrument is used for detecting single geometric error in the direct measurement method. For example, the level is often used for horizontal calibration, because the level measurement is characterized by simple operation, convenient use, and low price, and the relative accuracy is only $0.02 \mathrm{~mm} / \mathrm{m}$. The value collection and compilation are difficult, and the leveling linearity measurement is also difficult; thus, it is often used for short stroke rail 
linearity measurement. As the indirect measurement method produces cumulative error, the autocollimators are often used for measuring linearity, parallelism, and squareness, the measurement accuracy is $0.005 \mathrm{~mm} / \mathrm{m}$, higher than level measurement, but the larger the measurement range is, the larger is the deviation, and it is mainly used for moderate length rail linearity measurement. The laser interferometer is used for localization accuracy measurement, the measurement distance is long, the measurement speed is fast, the measurement accuracy is as high as $0.0004 \mathrm{~mm} / \mathrm{m}$, and the data can be collected continuously for rapid data compilation. It has very high interference resistance and very high price. It is mainly used in the CNC machine tools required of high accuracy. The development and design of current detection devices are described below. The objectives of this study include (1) evaluating the accuracy and effectiveness of different sensors, (2) comparing modeling and filtering parameters applied to the tilt sensors, and (3) investigating the accuracy influence of tilt sensors measures on CNC machine tools. The following Table 1 is the application of various level sensors [1, 2].

Ho et al. [3] proposed the bulk micromachining technology in 2006 to make a resistive microtilt sensor. Three sets of microelectrodes contacted the liquid to detect the resistance value. The resistance value between microelectrodes varied with the liquid surface. The level meter monitored the changes in resistance and voltage, so as to determine the tilt angle variation of level meter. The sensitivity was enhanced effectively when the formula and concentration of electrolyte were adjusted. According to the aerial view of resistive microsensing level meter, the sensing unit composed of positive electrode, negative electrode and reference electrode, and electrolyte is encapsulated in the silicon microstructure. When the tilt angle of level meter changes, the tilt angle displacement can be determined by sensing the resistance variation of electrode. In the operating diagram of resistive microsensing level meter, the detectable angular region of the device is \pm 60 , the sensor readout circuit frequency is $400 \mathrm{~Hz} \sim 1 \mathrm{kHz}$, the power supply is $5 \mathrm{~V}$ single power supply, and the voltage resolution is about $50 \mathrm{mV}$.

In 2010, Hsu and Bai et al. [4] hollowed partial structure of CMOS to make a microlevel meter, which monitored the equivalent capacitance to determine the horizontal tilt angle variation of the liquid surface, as shown in the operating diagram of CMOS-MEMS capacitive micro evel meter, according to sectional view of CMOS-MEMS capacitive microlevel meter. The FOX, air, and liquid formed three equivalent capacitors connected in series for sensing. The sensor readout circuit frequency was $100 \mathrm{kHz}$, the power supply was $3.3 \sim 5 \mathrm{~V}$ single power supply, the readable capacitance range was $20 \mathrm{fF}$ to $200 \mathrm{fF}$, and the corresponding output voltage was $2.18 \mathrm{~V}$ to $0.84 \mathrm{~V}$.

Bajic and Stupar [5] proposed a simple, low-cost, and highly sensitive fiber optic tilt sensor in 2012. The sensor comprised two optical fibers and a container with transparent liquid, and the container took half of total area of the equipment. In terms of the sensor measurement principle, when the liquid surface tilts, the optical fibers can measure the actual angle according to the refractions induced by liq- uid and air in the container. The result showed that the sensitivity was $1 \mathrm{~V} /{ }^{\circ}$, and the resolution was $0.02^{\circ}$.

In 2015, Salvador et al. [6] used PCB-MEMS to make a microfluidic capacitive tilt sensor. Circular metal channels of different sizes were fabricated on the PCB, filled with highly conducting fluid as dielectric constant. When the angle was tilted, the metal channel was partially filled with liquid, the rate of change in capacitance inside the channel was measured by two electrodes, the sensitivities to different sizes were $0.0019 \mathrm{pF}^{\circ}, \quad 0.0036 \mathrm{pF} /^{\circ}, \quad 0.0011 \mathrm{pF} /^{\circ}$, and $0.0016 \mathrm{pF} /{ }^{\circ}$, and the measurable range was $\pm 90^{\circ}$.

In 2014, Zou et al. [7] developed a pair of resonant strain gauges using DETF, and the mechanical resonance frequency and gravitational acceleration component variation of the input axis induced directly proportional movement of axial force. The test result showed that the tilt sensor could measure $\pm 90^{\circ}$, the temperature sensitivity was $500 \mathrm{ppb} / \mathrm{K}$, the system sensitivity error was about $0.007^{\circ} / \mathrm{K}$, the linear range within tilt measurement $\pm 20^{\circ}$ was better than $1.4 \%$, and the average response time was $0.8 \mathrm{~s}$.

Lee and Lee [8] developed a capacitive tilt sensor in 2013, a metal ball was used as the medium of sensor,and two electrodes were partitioned by a polystyrene tube in noncontact mode. When the metal ball in the sensor was tilted at an angle and two electrodes generated potential difference, the analog-to-digital converter was connected to the computer to obtain the actual angle. The measurable range was $\pm 90^{\circ}$, and linear position was presented outside $0^{\circ}-10^{\circ}$ low tilt angle.

Yang and Takamura [9] developed a multiprobe scanning system, using three laser interferometers and one autocollimator to measure nanoscale flat strip mirror contour. The laser interferometers detected the flat strip mirror fixed to the top of scan table, and the autocollimator measured the yaw error of scan table. The flat mirror contour and horizontal rectilinear motion error were reconstructed by using the simultaneous linear equation and least square method. The average of two standard deviations (95\%) of contour calculated in ten experiments was about $10 \mathrm{~nm}$.

Fan et al. [10] developed a novel six DOF measurement system (6DMS), which could measure six kinematic errors of linear platform simultaneously. Three collimated laser beams detected three relative distances (Yaw, Pitch, Roll) of object movement through Doppler effect. The lateral deviation of return light beam was detected by a beam splitter and two quadrant photodetectors. The measurement result showed that the positioning error was $0.01 \mu \mathrm{m}$ to $10 \mu \mathrm{m}$, the linear error was only $1 \mu \mathrm{m}$ within $\pm 0.1 \mathrm{~mm}$ measurement range, and the angular errors were 1 arcsec within \pm 50 arcsec measurement range. It can be easily combined with coordinate measurement of any working platform, such as linear platform, $X-Y$ platform, and machine tool, achieving higher efficiency and accurate measurement. Although a few researches have been carried out on the electrolytic tilt sensor, there have been few papers that focus on the measurement and intelligent for the CNC machine tool system, reviewing that date published in literature reveals that the phenomenon reported in this paper has not observed. 
TABLE 1: The comparison of the accuracy of different sensors.

\begin{tabular}{lcccc}
\hline Sensor type & Sensitivity & Repeatability & Measuring range & Axial \\
\hline Inductor (Wyler) & 2 arcsec & 3.6 arcsec & \pm 30 arcsec & Uniaxial \\
Capacitance (D. Benz) & $0.02^{\circ}$ & $0.04^{\circ}$ & $180^{\circ}$ & Uniaxial \\
Electrolyte (Fredericks) & $1 \mathrm{arcsec}$ & $5 \mathrm{arcsec}$ & $3^{\circ}$ & Uniaxial \\
Photoelectric (W.Y. Jywe) & $0.05 \mathrm{um}$ & $0.1 \mathrm{um}$ & $1800 \mathrm{arcsec}$ & Uniaxial \\
In this research and development equipment & $0.36 \mathrm{arcsec}$ & $3.6 \mathrm{arcsec}$ & $3^{\circ}$ & Biaxial \\
\hline
\end{tabular}

This publication presents the development and designs of high-precision level and tilt measurement equipment. Thus, the measuring equipment must have a mechanical design to make parallelism between the sensor and the clamping surface. In signal processing, convert analog signals into digital signals and apply the method of Fuzzy regression and Kalman that were for modeling and filtering, respectively. The equipment that wants calibration and verification includes stability, resolution, and repeatability. In the application, this measurement equipment is applied to $\mathrm{CNC}$ machine tools, and it can be synchronized to measure the $X / Y$ axis level accuracy and straightness measurement and can be installed build in the machine tool for monitoring.

\section{Principle of Measurement Module}

A flatness and level error measurement is carried out by taking a series of incremental height readings as the leveling is moved along the measurement path. On the basis of Figure 1, one can develop an equation for the straightness error in a given location, and then multiple straightness's are stacked to form level accuracy. Therefore, level and straightness are to be closely related [11]. According to ISO230 standard, the accuracy of dimension 500 800, $800 \sim 1250$, and $1250 \sim 2000 \mathrm{~mm}$ was $0.015,0.02$, and $0.25 \mathrm{~mm}$, respectively, [12].

$$
d_{n}=d_{n-1}+L \sin \alpha_{n}
$$

where $d_{n}$ is the straightness error in the $n$ point, $d_{n-1}$ is the straightness error in the previous point, $L$ is the distance between the measurements, and $\alpha_{n}$ is the measured deflection error.

2.1. Fuzzy Regression Analysis Modeling. The main purpose of the fuzzy regression analysis modeling is to convert the voltage value to the angle value. Traditional regression analysis assumes that the observed value is derived from actual dependent variable effect plus random error, which is to say that the dependent variable is a random variable with uncertainty. The compared fuzzy linear regression analysis with general regression model: the error of fitting between the fuzzy regression model and real value was regarded as the fuzziness of the model structure. Different fuzzy regression models are deduced according to different fitting criteria, CFC is a fuzzy linear regression model, as shown in Figure 2, where the small circle represents experiment data, the dotted line is the fitting curve calculated by using regres- sion model, the solid line is the boundary region of regression model, and these upper and lower boundaries are referred to Eqs. (3) and (4) [13].

Therefore, the regression coefficient is a fuzzy value, and the prediction value is a fuzzy value, wherein $A_{i}=\left(C_{i}, S_{i}\right)$ is the membership function of symmetrical triangle, and it has center $C_{i}$ and fuzzy half-width $S_{i}$. The input/output data are fixed values (crisp input and crisp output) $\left(x_{j}, y_{j}\right)$, and Tanaka used minimum fuzziness principle for fuzzy regression analysis; so, the uncertainty of fuzzy prediction is minimized, and the crisp output and fuzzy prediction shall be within certain limits. The principle is expressed as follows.

$$
\begin{gathered}
\text { Min } J=\sum_{j=1}^{m} s^{\prime}\left|x_{j}\right|, \\
S_{t} \cdot c^{\prime} x_{j}+(1-h) s^{\prime}\left|x_{j}\right| \geq y_{j}, \\
c^{\prime} x_{j}-(1-h) s^{\prime}\left|x_{j}\right| \leq y_{j}, j=1,2,3, \ldots \ldots \ldots, m, \\
s_{i} \geq 0, i=1,2,3, \cdots \cdots \cdots, n,
\end{gathered}
$$

where $m$ is the size of dataset, $n$ is the number of independent variables, $x_{j}$ represents the vector $\left\{x_{j 1}, x_{j 2}, \ldots, x_{j n}\right\}$ of No. $j$ observed value, $s$ represents the vector $\left\{s_{1}, s_{2}, \ldots, s_{n}\right\}$ of half of fuzzy regression coefficient, and $c$ represents the vector $\left\{c_{1}, c_{2}, \ldots, c_{n}\right\}$ of center of fuzzy regression coefficient. In order to solve the effect and limitation of different trends and abnormal values, Tanaka and Ishibuchi $[14,15]$ used the interval regression of QP. The result of QP has better central tendency than prior findings, and it is effective on solving the data with abnormal values. The model is expressed as follows:

$$
\begin{gathered}
J=k_{1} \sum_{j=1}^{m}\left(y_{j}-c^{\prime} x_{j}\right)^{2}+k_{2} \sum_{j=1}^{m} s^{\prime}\left|x_{j}\right|\left|x_{j}\right|^{\prime} s, \\
\text { St. } c^{\prime} x_{j}+(1-h) s^{\prime}\left|x_{j}\right| \geq y_{j}, \\
c^{\prime} x_{j}-(1-h) s^{\prime}\left|x_{j}\right| \leq y_{j} j=1,2,3, \cdots \cdots . ., m, \\
c_{i} \geq 0 i=0,1,2, ., \cdots \cdots, n,
\end{gathered}
$$

where $h$ value is the variable with crisp output data in the prediction interval, and $k_{1}$ and $k_{2}$ are two weighted factors. This model is used for balancing the least square principle and minimum fuzzy fitting criterion. There is a highly accurate model in the test of the $X$-axis which is $R^{2}=0.9764$ and 


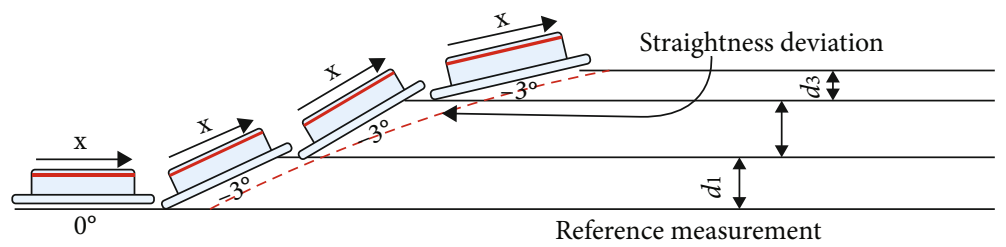

FIGURE 1: The relationship between straightness and level measurement.

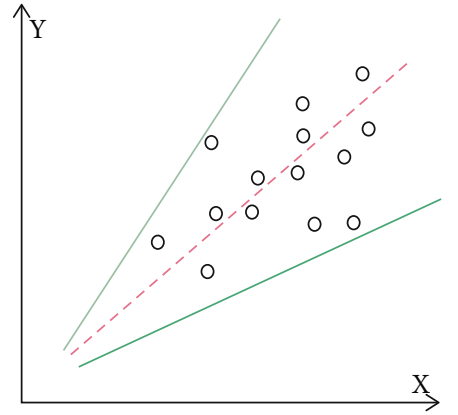

FIgURE 2: CFC fuzzy linear regression analysis.

$P=0.0506$ and $Y$-axis which is $R^{2}=0.9756$ and $P=0.0524$, as shown in Figure 3.

2.2. Kalman Filter. The Kalman filter method (KFM) is a high efficiency recursive filter for the processing linear dynamic system, and it can estimate the dynamic system state from incomplete measurement and noise measurement. The Kalman filter can be transformed into an equation, and two key points are "predicting" and "update." In the prediction stage, the state estimation of $k$ time length is generated by the state estimation of $k-1$ time length. In the update stage, the updated $k$ state estimation is completed by using the predicted $k$ state and the measured state of $k$ with a weight. The weight can be derived from the $k$ state noise and measured value of $k$ in Eq. (8). Finally, the $k$ state noise is updated by using the weight. The five major equations of Kalman filter are expressed as (10) and (11) [16, 17].

Kalman filtering prediction equation is as follows:

$$
\begin{gathered}
X_{k \mid k-1}=F_{k} X_{k-1 \mid k-1}+B_{k} u_{k-1}, \\
P_{k \mid k-1}=\mathrm{F}_{k} \mathrm{P}_{\mathrm{k}-1 \mid \mathrm{k}-1} F_{k}^{T} Q_{\mathrm{k}} .
\end{gathered}
$$

Kalman filtering update equation is as follows:

$$
\begin{gathered}
\mathrm{x}_{k \mid k}=X_{k \mid k-1}+K_{k}\left(Z_{\mathrm{k}}-H_{\mathrm{k}} X_{\mathrm{k} \mid \mathrm{k}-1}\right), \\
\mathrm{K}_{k}=\frac{P_{k \mid k-1} H_{k}^{T}}{H_{k} P_{k \mid k-1} H_{k}^{T}}+R_{k}, \\
\mathrm{P}_{k \mid k}=\left(1-K_{k} H_{k}\right) P_{k \mid k-1} .
\end{gathered}
$$

This study uses KFM that the leveling equipment and Wyler level meter are placed above the sine bar, making sure that the measured value is 0 . One point is captured per sec- ond in 30-minute measurement, and the measurement results are shown in Figure 4. The level detection equipment captures 16 bit $(0 \sim 65535)$ value, and the data before and after filtering are measured instantly in the humanmachine interface. According to the measurement results, the leveling equipment $X$ and $Y$ axes are improved by $94.1 \%$ and $86.2 \%$, respectively, before and after filtering. This research to selecting KFM has reason and advantages as follows: (1) can be used in the $X / Y$ multiaxis tilt sensor and multiple sequential measurements, (2) its the ability to provide the quality of the estimate and its relatively low complexity, and (3) deals effectively with the uncertainty due to noisy sensor data.

\section{Research Facilities and Process}

3.1. Sensor and System Integration. The external load or internal stress of the machine tool structure induces straightness error. This study develops an equipment of the leveling accuracy real-time measurement system, and the sensing equipment is an electrolyte level sensor. When a leveling error occurs, the bubble moves to the end on higher level, the difference in electrolyte liquid contact area generates voltage difference, and current level condition can be known by analyzing this voltage difference [18-20]. The aforesaid equipment is drawn in a circuit, as shown in Figure 5. The $X Y$ axis level meter exports PWM analog signals to the signal acquisition card (ADC), the signal acquisition card (ADC) exports digital signals to the MCU, the values are transferred to the PC end through Bluetooth communication (HM-10), and the software converts digital signals into angles which are easy to be read, as shown in Figure 6. The aforesaid firmware equipment is powered by 18650 rechargeable lithium battery. When the power is less than two grids, a message will be transferred to the PC through Bluetooth to inform the user of immediate charging, sensor measurement system, and mechanical structure to integration and built in, as shown in Figure 7.

\subsection{Leveling Equipment Accuracy Calibration and Measurement}

3.2.1. Stability Measurement. When the leveling accuracy real-time measurement system is completed, the stability test shall be performed to analyze the long-term stable running ability of measurement equipment. When the measurement system is set at a fixed angle for long-term measurement, the cumulative error and noise are likely to cause stability deterioration, which increases with test time. 

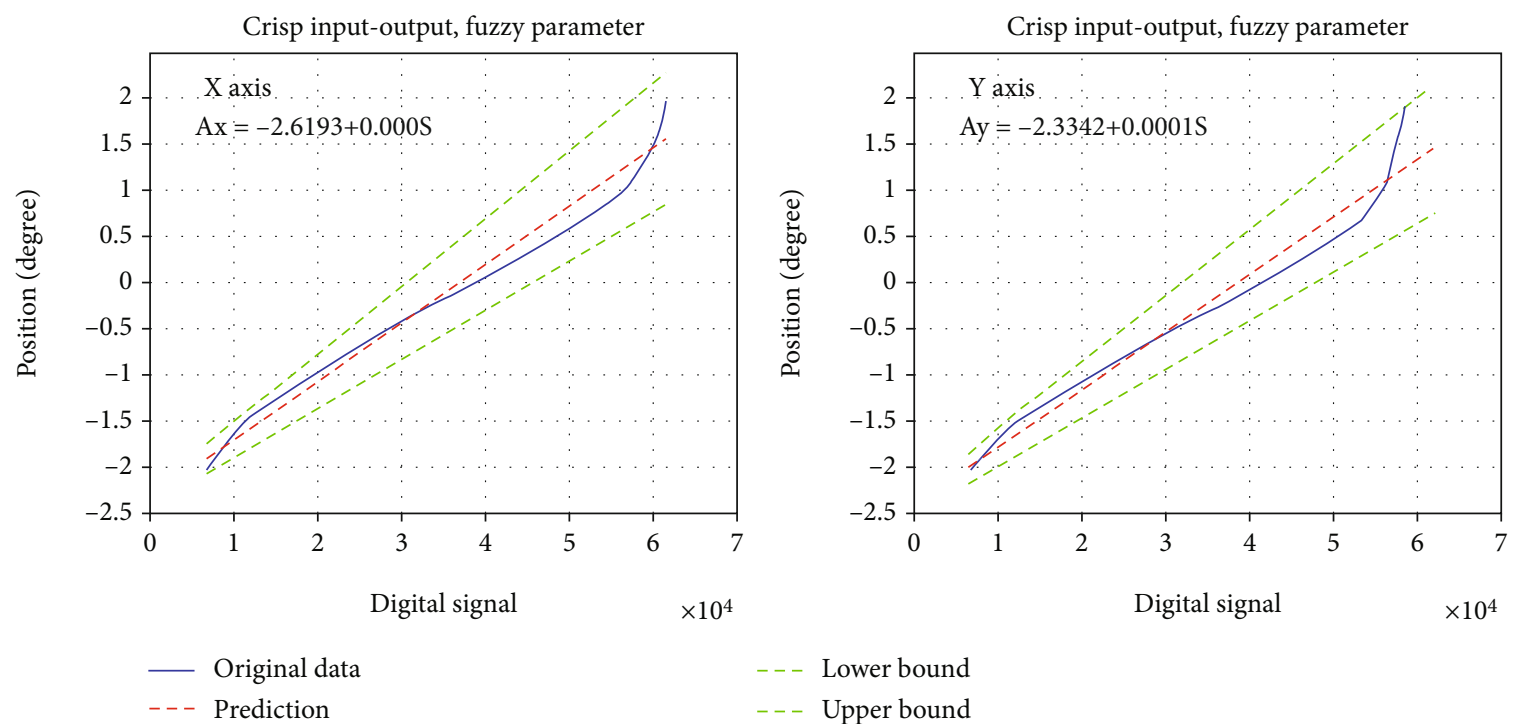

Figure 3: Fuzzy regression analysis prediction chart.

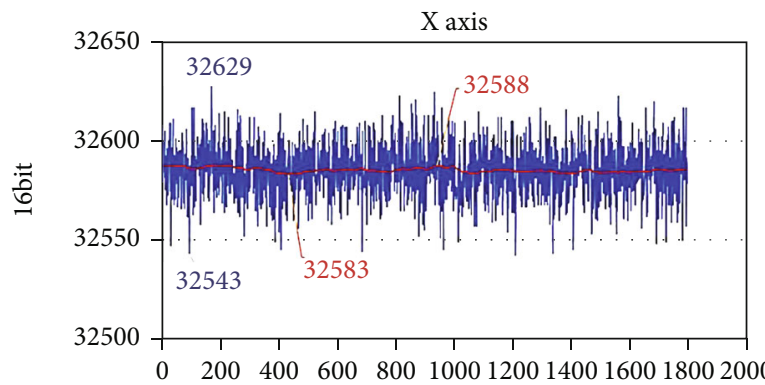

Time (sec)

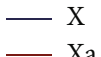

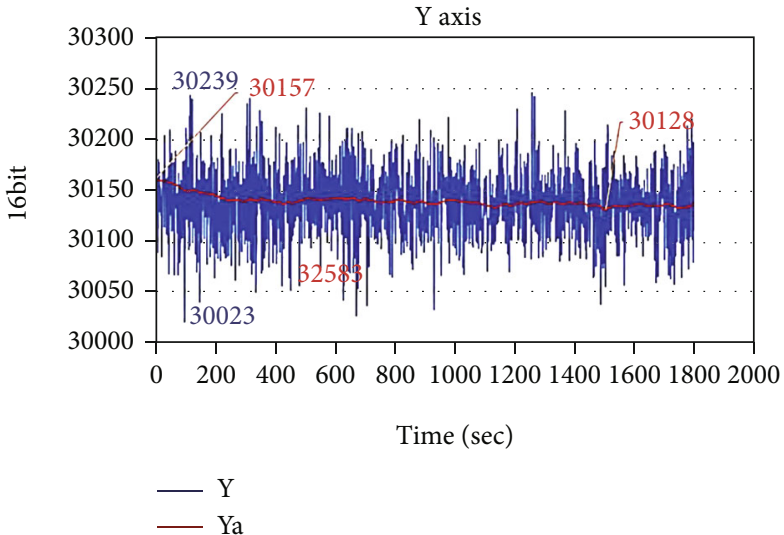

Figure 4: $X / Y$ axis measured values before and after filtering.

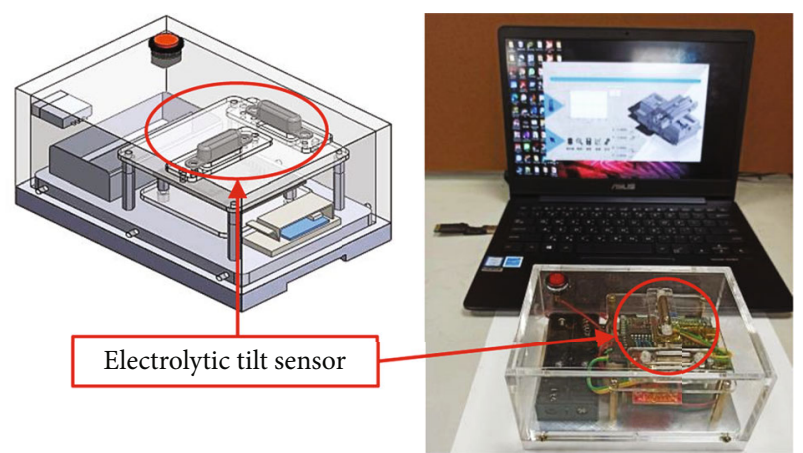

FIGURE 5: Electrolytic tilt sensor measurement system.

In terms of digital level adjustment detection device in this study, the sensor is placed on the granite platform and kept still for a period of time, and then the test begins in steady state. One point is captured per second in one-hour test, there are 3,601 points captured, and seven experiments are performed continuously. The data are reduced into the capability of accuracy (Ca) for inspection of digital level adjustment detection device, so as to check whether the measured value of digital level adjustment detection device reaches the accuracy requirement. The measured data are analyzed, and the result is made into Ca value grade classification table to show the usability of this detection device, where $\bar{x}$ represents the average of measurement result, $\mu$ is the sum of upper and lower specification limits, USL is the upper specification limit, and LSL is the lower specification limit [21]. According to the above table, the maximum $X$ -axis $\mathrm{Ca}$ value is $1.63 \%$, the minimum $\mathrm{Ca}$ value is $0.02 \%$, the $Y$-axis maximum $\mathrm{Ca}$ value is $6.35 \%$, and the minimum $\mathrm{Ca}$ value is $0.64 \%$, as shown in Figure 8; so, this detection device is above grade $\mathrm{B}$ in the $\mathrm{Ca}$ value grade classification table, so as to monitor the system stability.

$$
C a=\frac{|\bar{x}-\mu|}{(U S L-L S L) / 2} \times 100 \% .
$$

3.2.2. Repeatability Measurement. The repeatability test is 


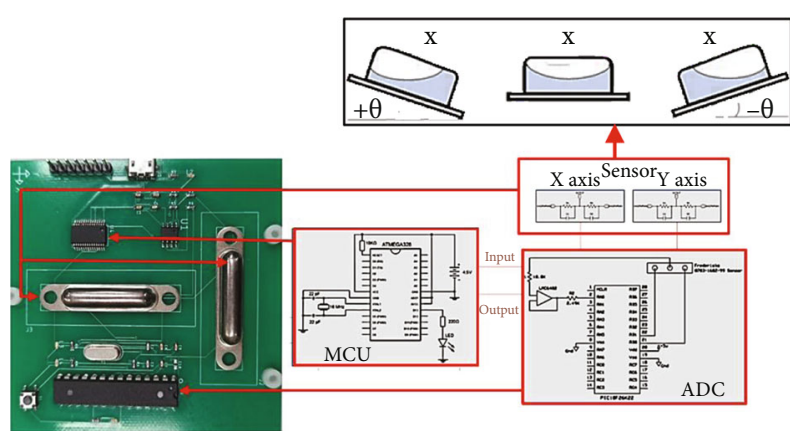

Figure 6: Circuit design drawing and schematic diagram of tilt sensor measurement.

performed to check whether the measurement equipment meets the specified measurement accuracy. The repeatability focuses on the variability of measurer. In the repeatability test of this study, the measurement equipment is placed above the sine bar, given an angle, and the value is recorded until steady state. After seven experiments, the data are compared and analyzed. One point is captured per second in 60minute measurement, and there are 3,601 points, as shown in Figure 9. The measured data are analyzed by software, the capability of precision $(\mathrm{Cp})$ value is obtained in process performance analysis, the histogram is obtained, and the $\mathrm{Cp}$ value grade is classified. The maximum $\mathrm{Cp}$ value is 7.07 that the minimum value is 2.3 , as shown in Figure 10. Therefore, this detection device is grade A. The larger the $\mathrm{Cp}$ value is, the more precise is the measurement equipment. The smaller the $\mathrm{Cp}$ value is, the poorer the measurement equipment, and redesign and modeling are required if necessary. This equipment is of superior repeatability [22].

3.2.3. Resolution Measurement. The resolution is defined as the minimum readable unit faithfully measured or detected by a measurement instrument. The resolution specification tolerance is $1 / 10$ or $1 / 5$. For example, the minimum measurement result of the digital level adjustment detection device in this study is $0.057^{\circ}\left( \pm 0.0001^{\circ}\right)$, the USL, central value, and LSL are $0.0571^{\circ}, 0.057^{\circ}$, and $0.0569^{\circ}$, respectively, and the measured value is $1 / 10$ of $0.0001^{\circ}$, i.e., $0.00001^{\circ}$ [23].

The resolution test is compared with the Wyler electronic level meter, and the maximum error value is $0.0002^{\circ}$ according to the test result; meaning, the digital level adjustment detection device of this study has very high accuracy. The following data are drawn, as shown in Figures 11 and 12 , more objectively showing that the detection device of this study is very excellent.

\section{Results and Discussion}

4.1. Static Measurement and Prediction of Machine Tool Foundation Adjustment. The leveling system developed in this study is used for CNC machine tool measurement, aiming to know the effect of different leveling accuracies on the machine tool motion straightness. The leveling accuracy and linear accuracy refer to international standards ISO230-1 [12]. This study uses three leveling accuracies for experiments, including $\pm 0.05 \mathrm{~mm} / \mathrm{m}, \pm 0.01 \mathrm{~mm} / \mathrm{m}$, and $\pm 0.005 \mathrm{~mm} / \mathrm{m}$. The machine leveling accuracy is obtained after machine tool foundation level adjustment, and the straightness of $X$-axis and $Y$-axis motions is measured. The experimental equipment is a $500 \mathrm{~mm}$ stroke machine tool. The machine specification is shown in Table 2. The digital level detection equipment developed in this study and commercially available Wyler level meter are placed in the middle of work table, as shown in Figure 13. First, the leveling accuracy is adjusted to different groups of leveling accuracy. Then, the $X$-axis and $Y$-axis motion straightness is measured. The values are compiled and analyzed.

This study adjusts No. 1, No. 2, and No. 5 anchor bolt to fully support the machine, and three correction principles are met. The adjustment process is based on No. 2 anchor bolt. The height and $X Y$ leveling accuracy are adjusted by No. 1 and No. 5 anchor bolts, as shown in Figure 14. In the $X$-axis measurement method, the total run is $500 \mathrm{~mm}$, the motion straightness measurement interval is $100 \mathrm{~mm}$, and the machine coordinates move from $(0,-180)$ to $(-500$, $-180)$. In the $Y$-axis measurement method, the total run is $360 \mathrm{~mm}$, the motion straightness measurement interval is $60 \mathrm{~mm}$, and the machine coordinates move from $(-250,0)$ to $(-250,-360)$. The $X$-axis and $Y$-axis level values are captured until the level value is in steady state whenever the measuring point is moved. The work table $X$-axis and $Y$ -axis shift positions are shown in Figure 15.

\subsubsection{Experimental Result of the X-Axis Kinematic Error} Pattern. The error pattern is tested and analyzed in the $X$ -axis motion of CNC machine tool, the $X / Y$ axis leveling accuracy will be described by experimental results of $\pm 0.05 \mathrm{~mm} / \mathrm{m}, \pm 0.01 \mathrm{~mm} / \mathrm{m}, \pm 0.005 \mathrm{~mm} / \mathrm{m}$, and $0 \mathrm{~mm} / \mathrm{m}$, the work table is located at machine coordinates $(-250$, -180 ), and the machine leveling accuracy is adjusted by torque wrench. The measured value is displayed on two equipment display interfaces, and the leveling accuracy is compared according to the measured value, guaranteeing coincident adjustment accuracy to avoid errors in the measurement result. The value is recorded until the value is in steady state after adjustment, and then the work table is moved to the starting point of machine coordinates $(0$, -180 ) and moved rightwards at measuring span of $100 \mathrm{~mm}$ to the machine coordinates $(-500,-180)$. The $X$ and $Y$ level values are captured until the value is in steady state in the measurement process, and there are 12 points captured.

The error range is $0.0328 \mathrm{~mm} / \mathrm{m}$ when the $X / Y$ leveling accuracy is 0.005 . When the $X / Y$ leveling accuracy is $\pm 0.01 \mathrm{~mm} / \mathrm{m}$, as the machine tool has reached the limit of accuracy, the machine tool motion straightness is increased by only $18 \%$ when the leveling accuracy is increased. The increase of accuracy is not large, but the accuracy of the detection device is higher than the $0.02 \mathrm{~mm} / \mathrm{m}$ of prior bubble level by at least $75 \%$.

According to Figure 16 that the different leveling accuracies have coincident trend of $X$-axis linear positioning error (EXX), the $X$-axis linear positioning trend result corresponding to worse leveling accuracy is worse. However, when the $X / Y$ leveling accuracy is -0.01 , and the linear positioning error (EXX) measurement result is larger than -0.005 


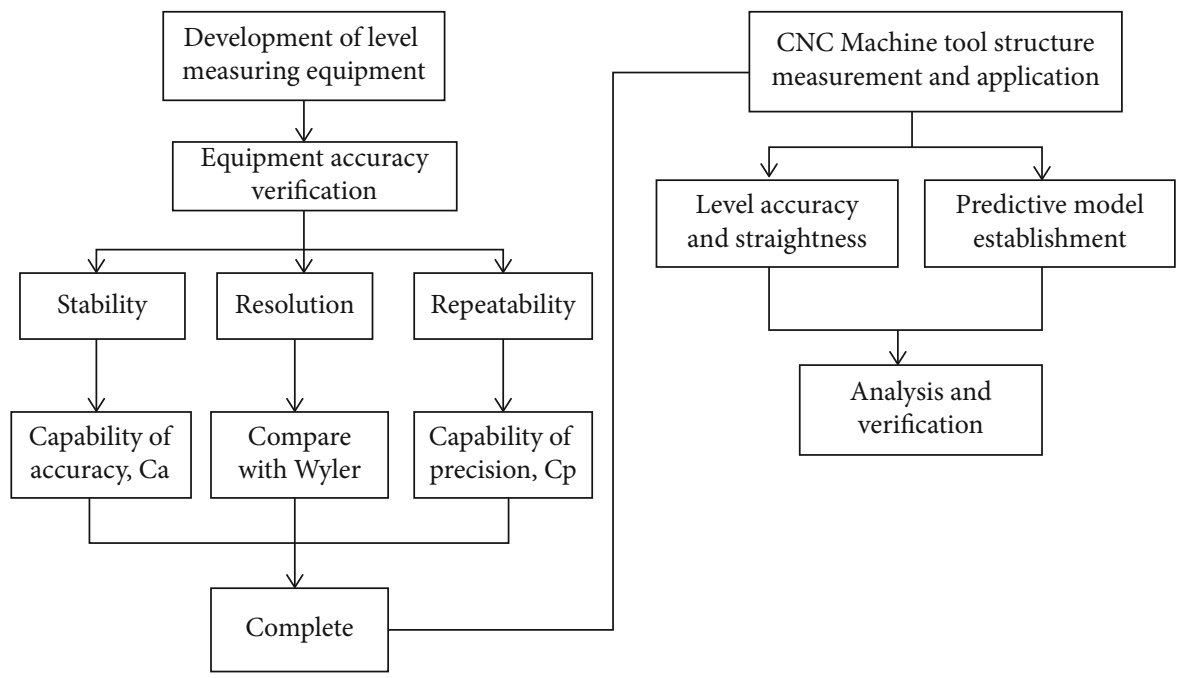

FiguRE 7: Sensor measurement system and mechanical structure to integration.
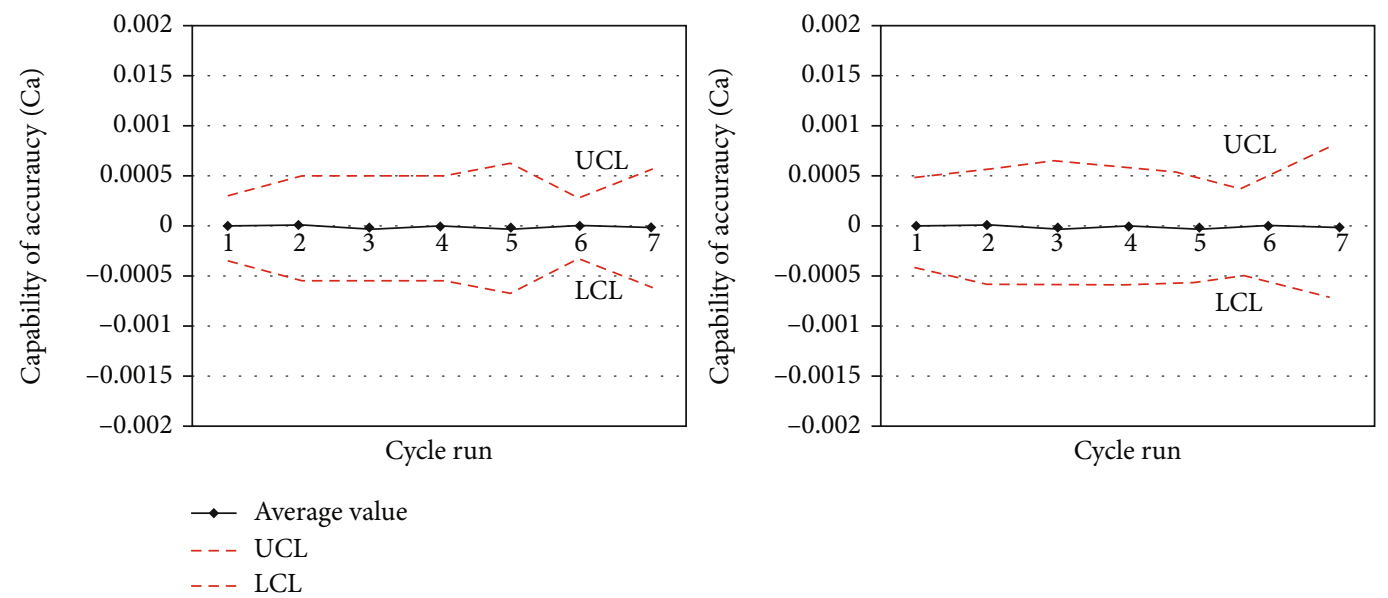

Figure 8: $X / Y$ axis Ca value analysis result.
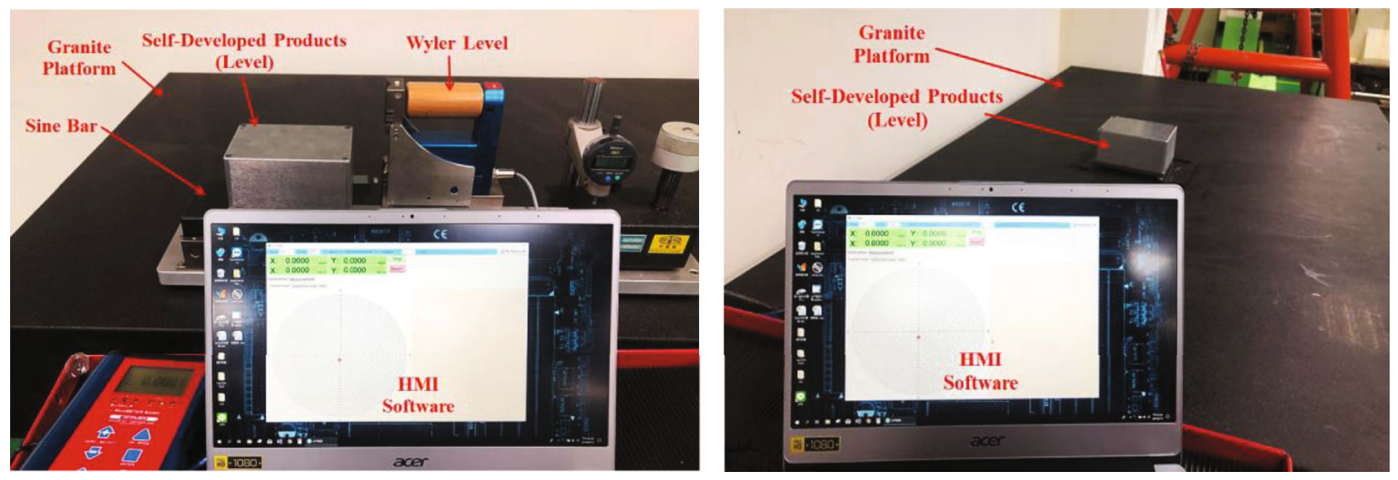

FIGURE 9: Experimental setup for repeatability and stability measurement.

at machine coordinates $(-250,0)$ and $(-250,-500)$. The maximum linear positioning errors corresponding to two leveling accuracies at $(-250,0)$ are $-0.0206 \mathrm{~mm} / \mathrm{m}$ and $-0.0234 \mathrm{~mm} / \mathrm{m}$, and that at $(-250,-500)$ are $0.0107 \mathrm{~mm} / \mathrm{m}$ and $0.0047 \mathrm{~mm} / \mathrm{m}$. The measuring points other than the aforesaid two points have very close measurement results of leveling accuracy (-0.01, -0.01) and (-0.005, -0.005); meaning, this machine tool has reached the limit of leveling accuracy, and the accuracy is within ISO $0.02 \mathrm{~mm} / \mathrm{m}$.

Whether the corresponding identical leveling accuracies in positive and negative directions are symmetrical and the values are close, when the $X / Y$ leveling accuracies are 0.01 


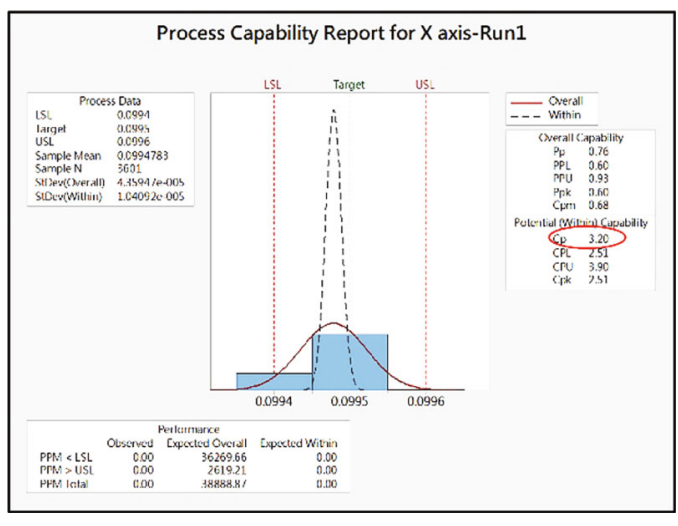

(a)

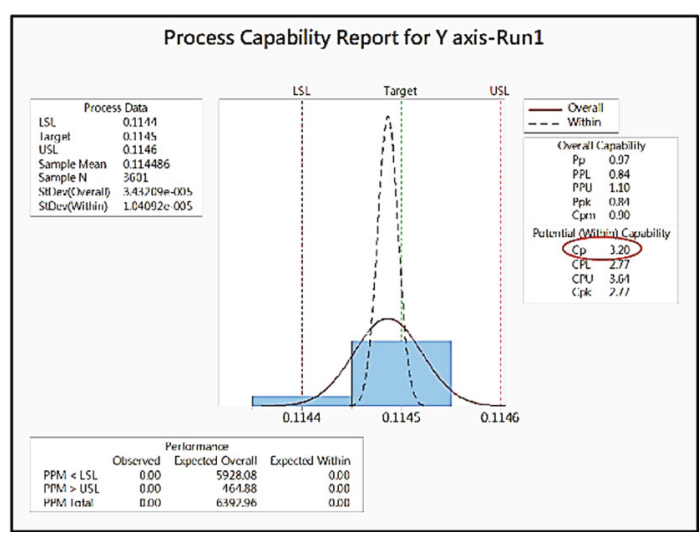

(b)

Figure 10: Repeatability test 6 sigma histogram: (a) $X$-axis and (b) $Y$-axis.

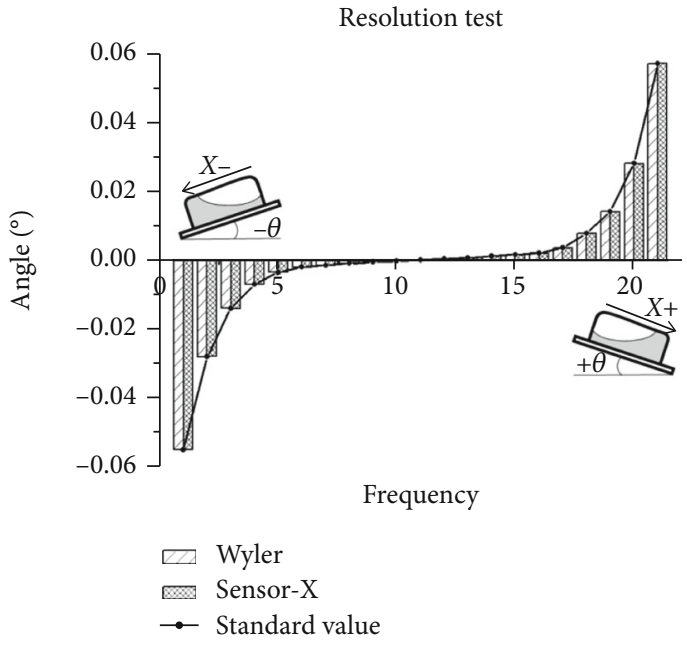

FIgURE 11: $X$-axis resolution test curve diagram.

and -0.005 , the maximum error rate is $4 \%$, and the maximum difference of absolute values in positive and negative directions is $0.0003 \mathrm{~mm} / \mathrm{m}$. It is the largest difference among the following three groups at $( \pm 0.005, \pm 0.005)$.

The maximum error range of seven experiments at $(-0.05,-0.05)$ is as high as $0.0229 \mathrm{~mm} / \mathrm{m}$, and the error range has exceeded the medium grade machine tool criterion $0.02 \mathrm{~mm} / \mathrm{m}$. The leveling accuracy must be adjusted immediately. When the leveling accuracy is lower than $(0,0)$, the maximum error value is at $(0,-180)$, and the maximum error of leveling accuracy larger than $(0,0)$ is at $(-400,-180)$ and $(-500,-180)$, coincident with the maximum error value of $X$-axis linear positioning error (EXX). Therefore, the machine $X$-axis kinematic error pattern ascends from left to right.

Whether the same leveling accuracy and maximum roll error value corresponding to positive and negative directions of $X$-axis roll angle (EAX) are directionally symmetrical, the values are close can be known. When the $X / Y$ leveling accuracy is \pm 0.01 , the maximum error rate is $9 \%$, and the difference between the two absolute values is $0.0014 \mathrm{~mm} / \mathrm{m}$. When the $X / Y$ leveling accuracy is \pm 0.05 , the difference

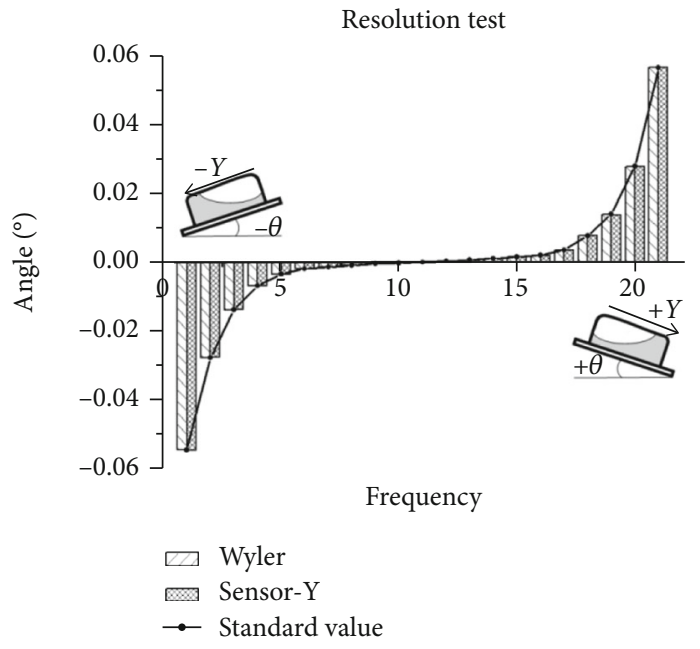

Figure 12: $Y$-axis resolution test curve diagram.

between the two angles is $0.0017 \mathrm{~mm} / \mathrm{m}$, which is the largest among three groups, as shown in Figure 17.

4.1.2. Experimental Result of the $Y$-Axis Kinematic Error Pattern. The error pattern is tested and analyzed in $Y$-axis motion of CNC machine tool, and $\pm 0.05 \mathrm{~mm} / \mathrm{m}$, $\pm 0.01 \mathrm{~mm} / \mathrm{m}, \pm 0.005 \mathrm{~mm} / \mathrm{m}$, and $0 \mathrm{~mm} / \mathrm{m}$ are described in various groups of $X / Y$ leveling accuracy. First, the work table is moved to machine coordinates $(-250,-180)$, and then the equipment developed in this study and Wyler level meter are placed in the middle of work table. When the testing instrument values are stable, the machine leveling accuracy is adjusted by torque wrench, and the measured value is observed, guaranteeing coincident adjustment accuracy to avoid errors in measurement result. After adjustment, the value is recorded when the value is in steady state. For straightness measurement, the work table is moved to the starting point of machine coordinates $(-250,0)$ and to machine coordinates $(-250,-360)$ towards spindle at measuring span of $60 \mathrm{~mm}$. The $X$ and $Y$ level values are captured until the values are in steady state in the measurement process, and there are 14 points captured. 
TABLE 2: Experimental machine specification.

\begin{tabular}{lccc}
\hline Item & Specification & Item & Specification \\
\hline Spindle speed & $24000 \mathrm{rpm}$ & Work table size & $400 \mathrm{~mm} \times 650 \mathrm{~mm}$ \\
Maximum spindle motor power & $7.5 \mathrm{~kW}$ & Maximum average load of work table & $300 \mathrm{~kg}$ \\
Spindle taper & BT30 & Quantity of cutting tools & 16 \\
$X \times Y \times Z$ stroke & $500 \mathrm{~mm} \times 360 \mathrm{~mm} \times 300 \mathrm{~mm}$ & Machine weight & $2.5 \mathrm{~m} . t$. \\
Distance from spindle nose and work table & $180 \mathrm{~mm}$ & & \\
\hline
\end{tabular}
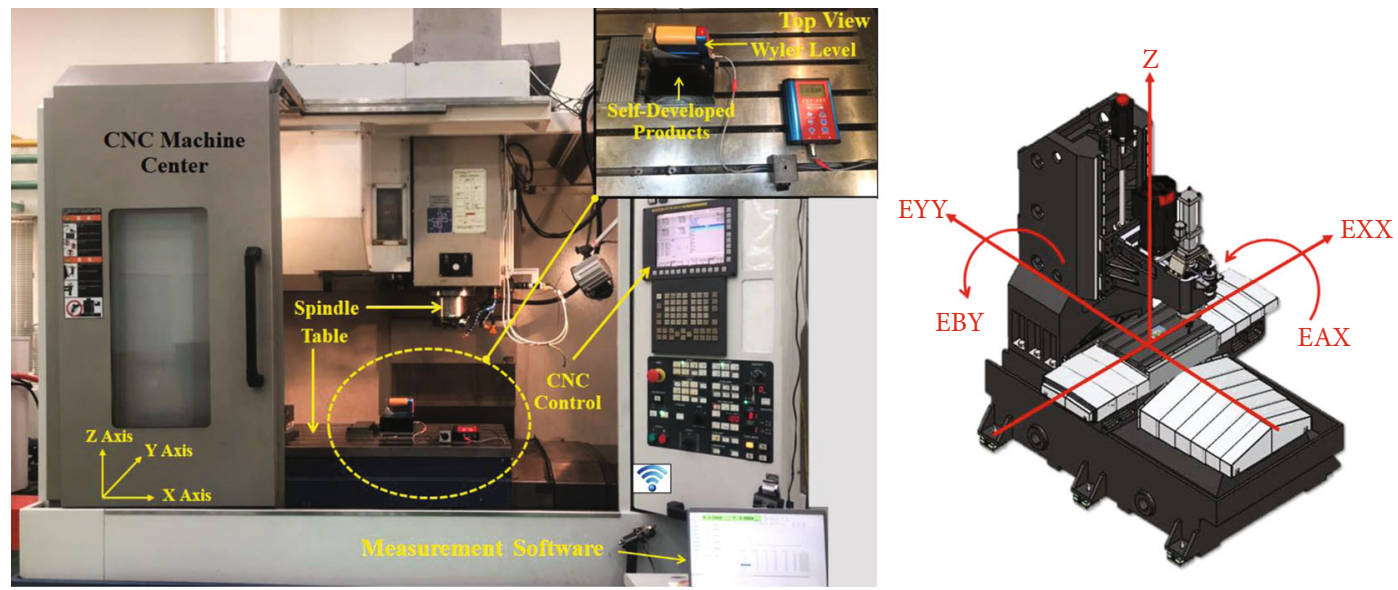

FIgURE 13: Real machine test setup.

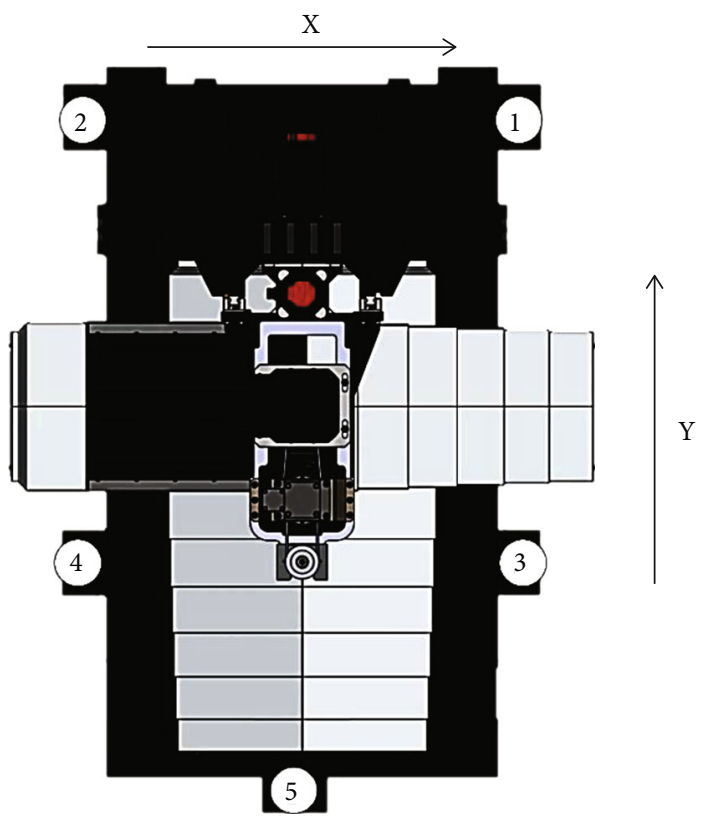

FIGURE 14: Schematic diagram of machine tool foundation.

Figure 18 shows the $Y$-axis linear positioning error (EYY) of different leveling accuracies, and the maximum linear positioning error values corresponding to various leveling accuracies are $0.0501 \mathrm{~mm} / \mathrm{m}, 0.0115 \mathrm{~mm} / \mathrm{m},-0.0072 \mathrm{~mm} / \mathrm{m}$, $-0.0118 \mathrm{~mm} / \mathrm{m}, \quad-0.0148 \mathrm{~mm} / \mathrm{m}, \quad 0.0178 \mathrm{~mm} / \mathrm{m}$, and $-0.059 \mathrm{~mm} / \mathrm{m}$. Therefore, the $Y$-axis linear positioning and yaw angle measurement results corresponding to worse leveling accuracy are worse. When the $X / Y$ leveling accuracy is $\pm 0.01 \mathrm{~mm} / \mathrm{m}$, as the machine tool has reached the limit of accuracy, whether the same leveling accuracy and maximum roll error value corresponding to positive and negative directions of $Y$-axis linear positioning (EYY) are directionally symmetrical, and the values are close. The error rate is $20 \%$ when the $X / Y$ leveling accuracy is -0.005 . After the two absolute values are taken, the difference among three groups is $0.0007 \mathrm{~mm} / \mathrm{m}$.

On Figure 19 that shows the $Y$-axis yaw angle error (EBY) of different leveling accuracies, the maximum linear positioning error values corresponding to various leveling accuracies are $0.0525 \mathrm{~mm} / \mathrm{m}, 0.015 \mathrm{~mm} / \mathrm{m}, 0.0093 \mathrm{~mm} / \mathrm{m}$, $0.0006 \mathrm{~mm} / \mathrm{m}, \quad-0.0077 \mathrm{~mm} / \mathrm{m}, \quad-0.014 \mathrm{~mm} / \mathrm{m}$, and $-0.0526 \mathrm{~mm} / \mathrm{m}$. When the leveling accuracy is lower than $\pm 0.01 \mathrm{~mm} / \mathrm{m}$, the experimental results are very close, and there are slight changes; meaning, the machine tool has reached the limit of accuracy. Whether the same leveling accuracy and maximum yaw angle error value corresponding to positive and negative directions of experimental results of $Y$-axis yaw angle (EBY) are symmetrical and the values are close, the maximum error rate is $10 \%$ when the leveling accuracy is $( \pm 0.005, \pm 0.005)$. It is the maximum error value of three experiments. The error value of positive and negative values at $( \pm 0.05, \pm 0.05)$ is $0.0008 \mathrm{~mm} / \mathrm{m}$, the largest difference of three groups.

4.2. Kinematic Error Pattern Modeling and Prediction. The modeling is estimated by factorial design screening 


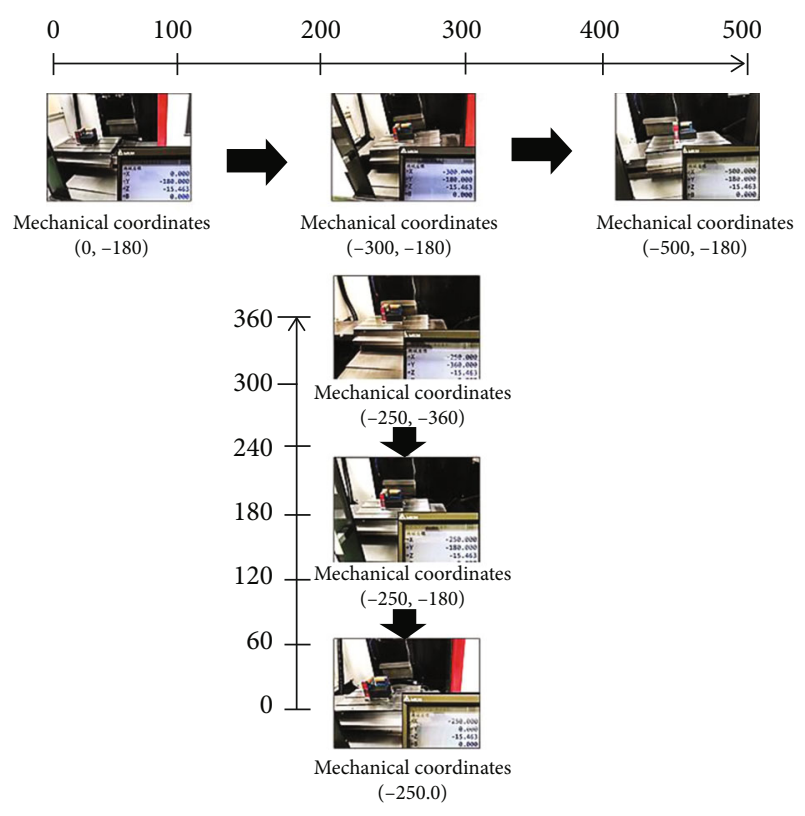

FIgURE 15: Work table shift positions.

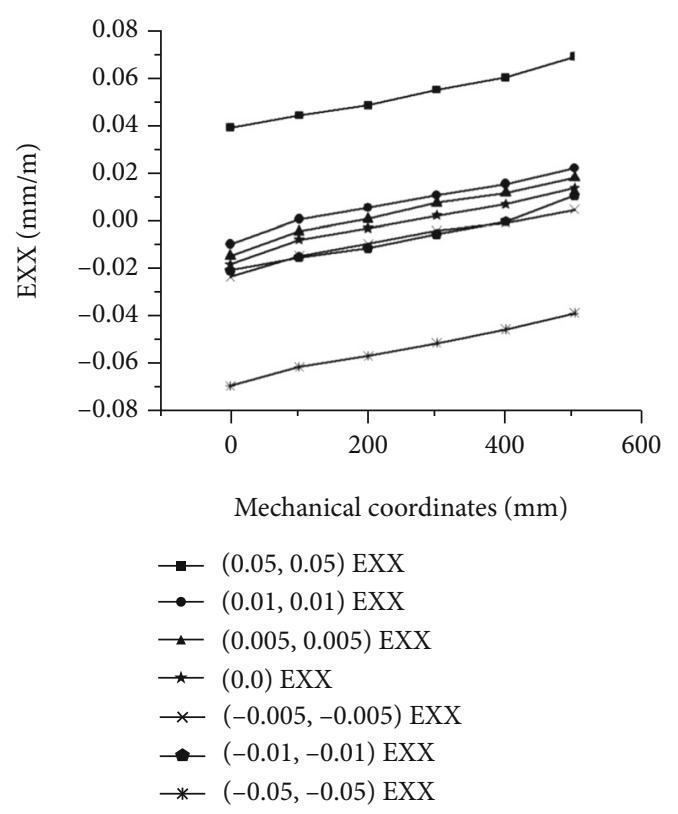

FIgURE 16: $X$-axis linear positioning error (EXX).

experiment according to the obtained experiment data. The number of experiments and the suitable criterion for resolution are determined, and the experimental results are used for regression analysis. The items of insignificant factors are removed by the reverse scalping method to obtain the regression equation. The analytic experiment, pattern drawing, and numerical assay are performed. The $R^{2}$ coefficient of determination is calculated at significant difference level of $\alpha=0.05$ by using ANOVA and statistical software, and the decision is made by the $F$-test and $t$-test. Related analysis charts are exported, including normal distribution diagram and residual analysis diagram of values, so as to check

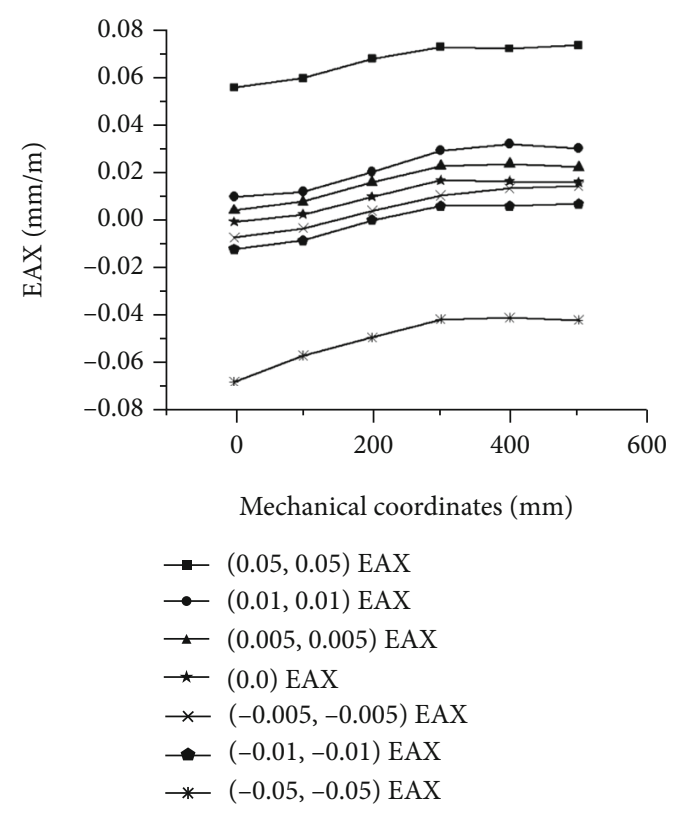

FIgURE 17: $X$-axis roll angle error (EAX).

whether the regression analysis model is accurate, described in the following sections [24].

4.2.1. Estimation Model of X-Axis Leveling Accuracy for Linear Error. The estimation model has two methods to experimentally screen out the significant factors, one is full factorial experiment, clarifying which group is significant factors and which are insignificant factors, or according to the significance of interaction. The other one is fractional factorial experiment, but partial factors need related evidence data and experience. This study discusses the influence on kinematic error pattern within $\pm 0.05 \mathrm{~mm} / \mathrm{m}$ leveling accuracy of machine tool; so, the full factorial analysis method is used, there are 36 experiments, and there are 144 experimental results of EXX, EAX, EYY, and EBY kinematic error patterns, fitting second-order regression model [25].

$$
Y=\beta_{0}+\beta_{1} X_{1}+\beta_{2} X_{2}-\beta_{3} X_{1} X_{2}-\beta_{4} X_{1}^{2}+\beta_{5} X_{2}^{2}
$$

wherein $X_{1}$ is the $X$-axis leveling accuracy $(\mathrm{mm} / \mathrm{m}) ; X_{2}$ is the $Y$-axis leveling accuracy $(\mathrm{mm} / \mathrm{m}) ; \beta_{0}, \beta_{1} \ldots . ., \beta_{5}$ are coefficients.

The aforesaid data are processed by ANOVA, and related test coefficients $R^{2}, F$ value, $P$ value, and $t$ value are used for experimental analysis. The significant difference level is set as $\alpha=0.05$ in this experiment, $F$ test $F=535.43$ $>F_{(0.05,5,30)}=2.5336$, and $P$ test $P<0.05$, according to the following table, and the regression model has passed $F$ value and $P$ value tests, but the $Y$ factor, crosseffect factor, and second-order factor do not conform to $F$ value and $P$ value tests; meaning, the second-order regression model is insignificant, the $Y$ factor has lower contribution, and there may be significant factors in the first-order regression model. Therefore, the reverse scalping method is used after 


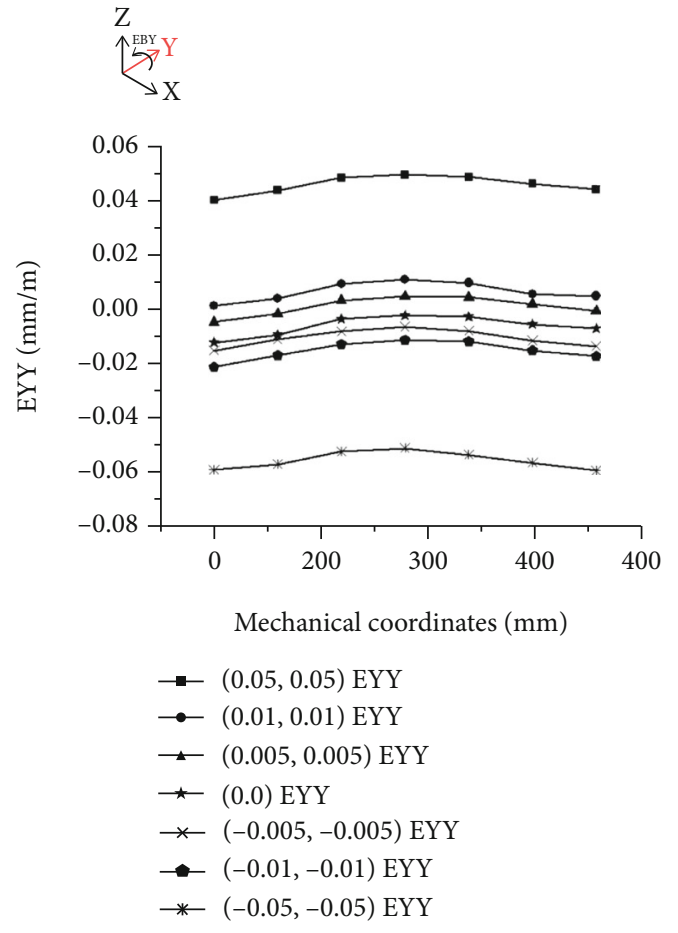

Figure 18: $Y$-axis linear positioning error (EYY).

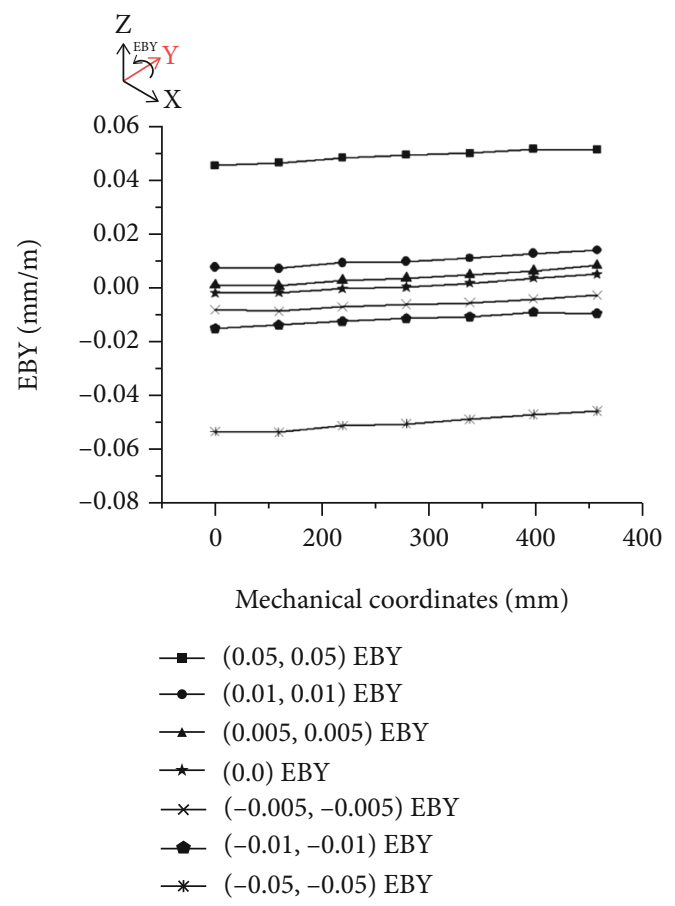

Figure 19: $Y$-axis yaw angle error (EBY).

adjustment to look for feature points and obtain applicable regression equation.

The term of significant factor is found by using reverse scalping method, the regression model ANOVA of machine tool $X$-axis linear positioning error (EXX) is shown in Table 3, the main significant factor is $X$, and the $F$ value is
TABLE 3: First-order regression model ANOVA of $X$-axis linear positioning error (EXX) after adjustment.

\begin{tabular}{lccccc}
\hline Source & DF & Adj SS & Adj MS & $F$ value & $P$ value \\
\hline Regression & 1 & 0.031471 & 0.031471 & 2479.86 & 0.000 \\
$X$ & 1 & 0.031471 & 0.031471 & 2479.86 & 0.000 \\
Error & 34 & 0.000431 & 0.000013 & & \\
Total & 35 & 0.031902 & & & \\
\hline
\end{tabular}

Standard deviation, $S=0.0035624$ and $R-s q=98.65 \%$.

TABLE 4: First-order regression model individual coefficient analysis of $X$-axis linear positioning error (EXX) after adjustment.

\begin{tabular}{lccccr}
\hline Term & Coef & SE Coef & $t$ value & $P$ value & VIF \\
\hline Constant & 0.000356 & 0.000594 & 0.60 & 0.553 & \\
$X$ & 0.9995 & 0.0201 & 49.80 & 0.000 & 1.00 \\
\hline
\end{tabular}

larger than the standard value, as shown in Eq. (18), the $P$ value is $\leq 0.001$ than $\alpha=0.05$, individual coefficient analysis is shown in Table 4 , and the $t$ value exceeds $t_{0.025}=2.0322$ of bilateral $t$ distribution, as shown in Eq. (18); so, the aforesaid test values have passed criteria, and the regression equation is expressed as Eq. (19).

$$
\begin{gathered}
F=2479.86>F_{(0.05,1,34)}=4.13 \\
t>t_{\alpha / 2}=t_{0.025}=2.0322 \\
\mathrm{EXX}=0.000356+0.9995 X
\end{gathered}
$$

The built first-order regression model is used for residual analysis, to check whether the regression model is of normality and homogeneity of variance and independence. Figure 20 shows the assumed variation trend is met; so, the regression equation feasibility is met.

In the second-order regression model ANOVA of $X$-axis roll angle (EAX), the most significant factor screened by the reverse scalping method is $Y$, the $F$ value is $2479.86>$ $F_{(0.05,1,34)}=4.13$ in ANOVA, it is rejected in the null hypothesis and $P$ value $<0.05$, and the calibration coefficient is $R^{2}=0.9865$; meaning, the total variation of this regression model is as high as $98.65 \%$, the fitness is very high, and $t$ value exceeds bilateral test $t_{0.025}=2.0322$, as shown in Figure 21. So, the aforesaid test values have passed the criteria, and the regression equation is expressed as Eq. (20).

$$
\mathrm{EAX}=0.000097+1.0046 Y \text {. }
$$

4.2.2. Estimation Model of $Y$-axis Leveling Accuracy for Linear Error. The $Y$-axis linear positioning error (EYY) data are tested by ANOVA and correlation test coefficient, the significant factor obtained by the reverse scalping method is $Y$, the $F$ value in ANOVA is $67337.91>F_{(0.05,1,34)}=4.13$ , and it thus rejects the null hypothesis and $P$ value $<0.05$. The calibration coefficient is $R^{2}=0.9865$; meaning, the total variation of this regression model is as high as $98.65 \%$, and 
Residual Plots for EBY
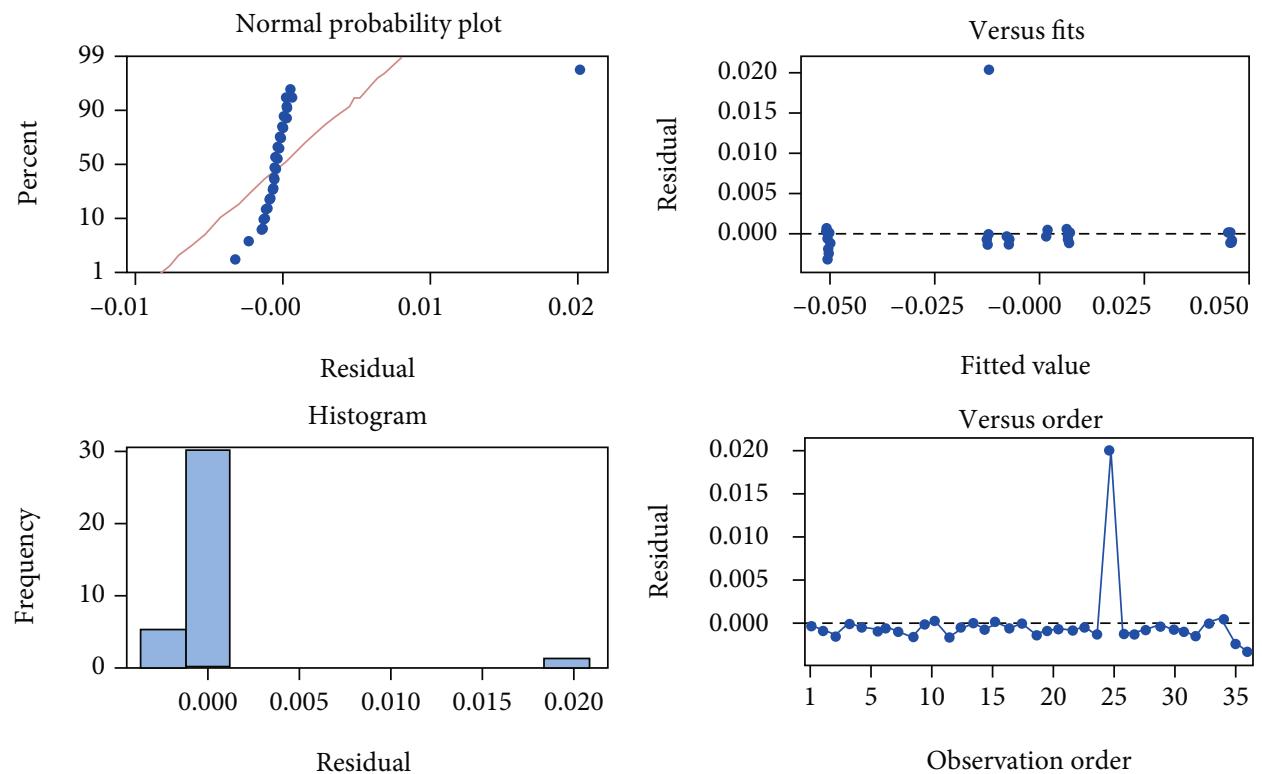

FIgUre 20: Residual analysis of $X$-axis linear positioning error (EXX).

Residual Plots for EBY
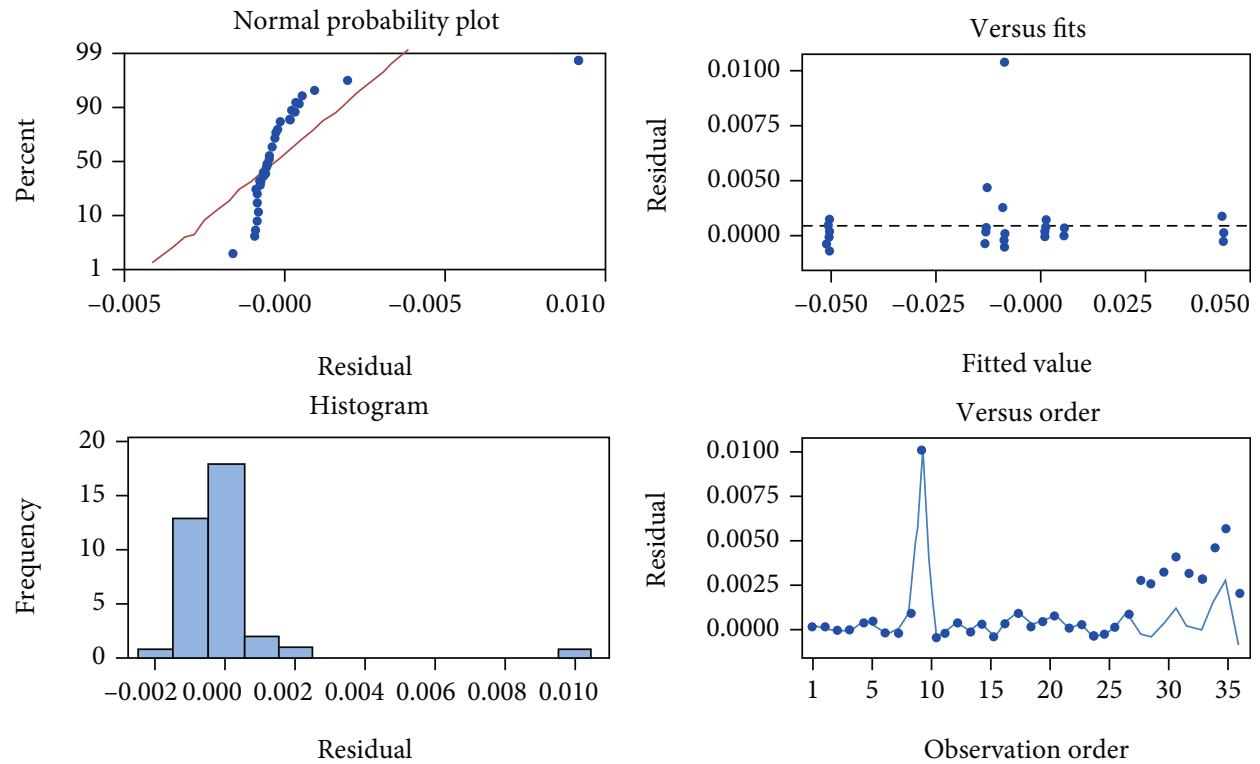

FIgURE 21: Residual analysis of $X$-axis roll angle error (EBY).

the fitness is very high, as shown in Figure 22 and Eqs. (5) and (6). The aforesaid test values have passed criteria, and the regression is in Eq. (21).

$$
\mathrm{EYY}=-0.000181+1.00287 Y \text {. }
$$

The collected $Y$-axis yaw angle error (EBY) data are tested by ANOVA and correlation test coefficient, the $F$ value in ANOVA is $43289.14>F_{(0.05,1,34)}=4.13$ and $P$ value $<0.05$, and it rejects the null hypothesis and calibration coef- ficient $R^{2}=0.9992$; meaning, the total variation of this regression model is as high as $99.92 \%$, and the fitness is very high. The $t$ value exceeds bilateral test $t_{0.025}=2.0322$, as shown in Eq. (22); so, the aforesaid test values have passed the criteria, and the regression equation is obtained, as shown in Figure 23.

$$
\mathrm{EBY}=-0.000344+1.00514 X
$$

4.3. Experiment Validation Analysis and Testing. Three groups of leveling accuracy and percentage error are selected 
Residual Plots for EBY
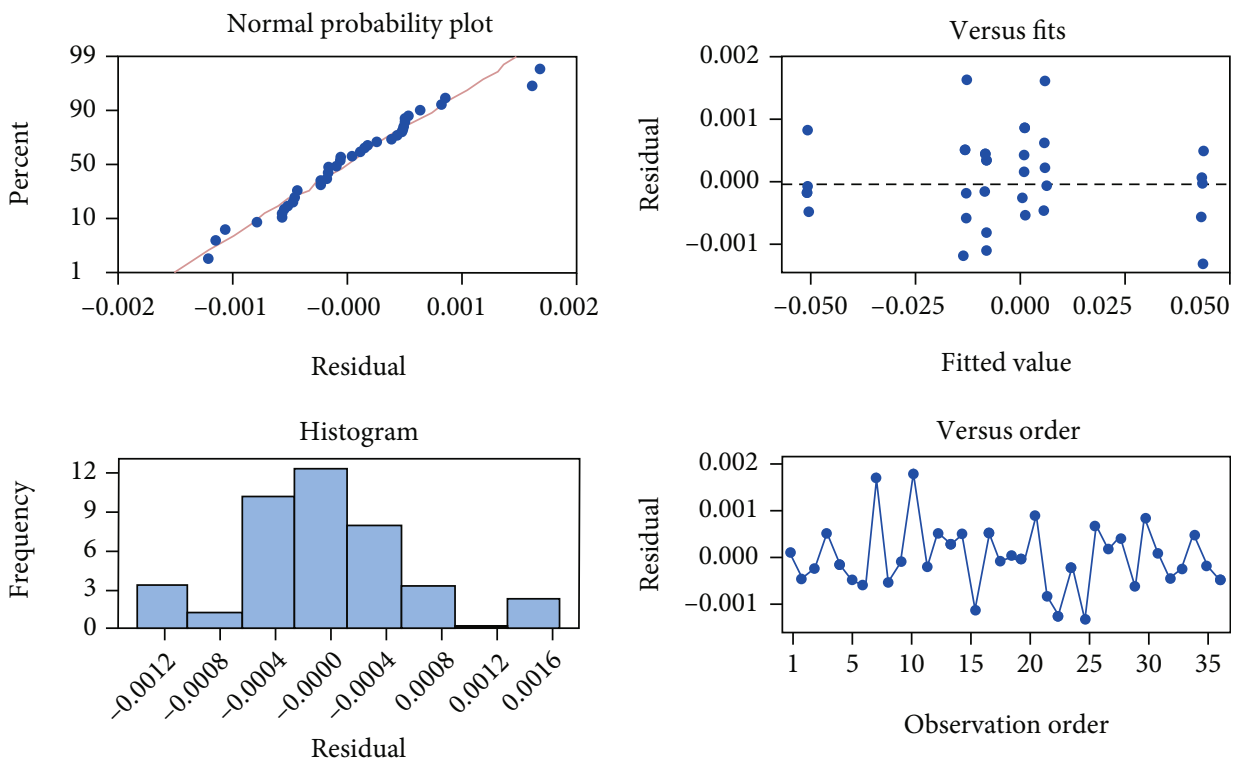

Figure 22: Residual analysis of $Y$-axis linear positioning error (EYY).
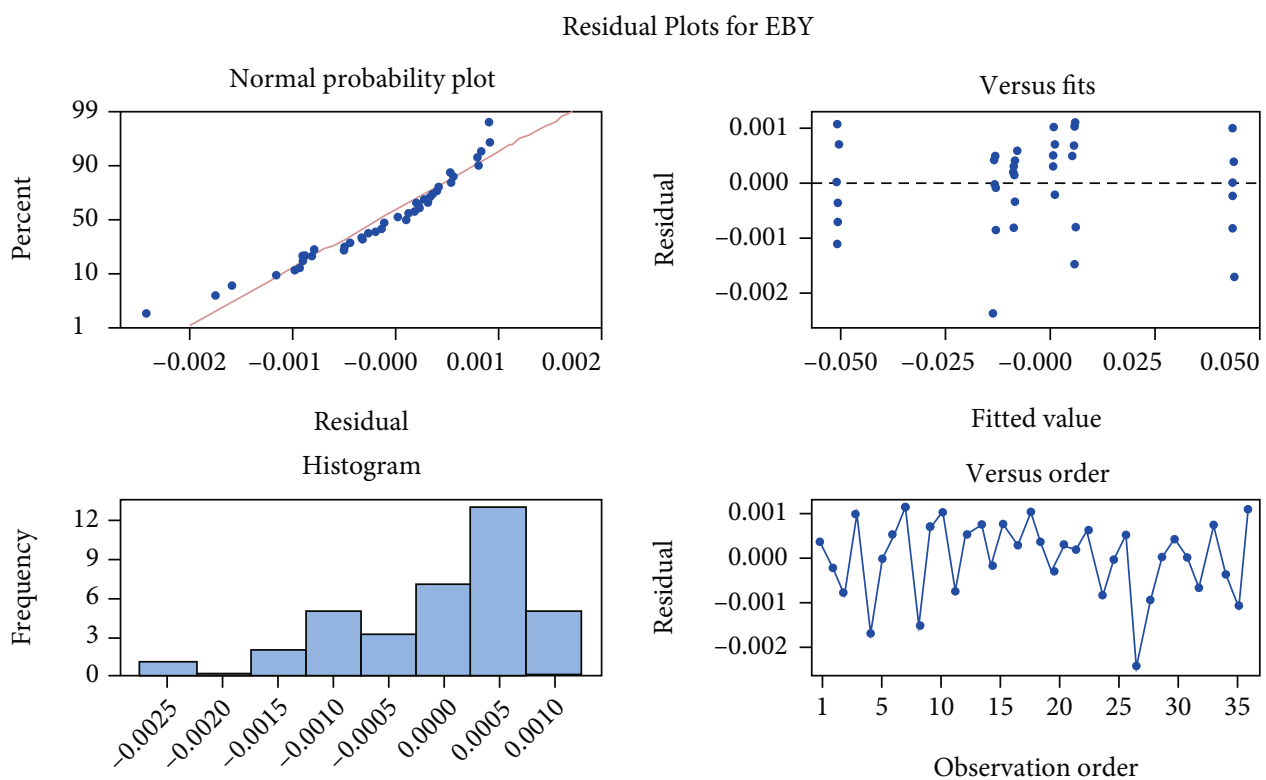

Residual

Figure 23: Residual analysis of $Y$-axis yaw angle error (EBY).

for operations in the validation experiment, making sure that the validation experiment data are in the prediction range of regression equation, so as to estimate the kinematic error patterns EXX, EAX, EYY, and EBY corresponding to different leveling accuracies of regression equation. According to three groups of validation data in Table 5, when the $X Y$ leveling accuracy of group A is $0.02 \mathrm{~mm} / \mathrm{m}$, the percentage error is less than $2 \%$, the measured kinematic error pattern values are $0.0205 \mathrm{~mm} / \mathrm{m}, 0.0198 \mathrm{~mm} / \mathrm{m}, 0.0202 \mathrm{~mm} / \mathrm{m}$, and $0.0195 \mathrm{~mm} / \mathrm{m}$, and the prediction values are $0.0203 \mathrm{~mm} / \mathrm{m}, \quad 0.0202 \mathrm{~mm} / \mathrm{m}, \quad 0.0199 \mathrm{~mm} / \mathrm{m}$, and
$0.0198 \mathrm{~mm} / \mathrm{m}$, wherein the maximum error in EAX is 0.0004 , and the percentage error is $2 \%$. According to the validation experiment of group B, the EXX has the maximum error percentage $8.3 \%$ among four error patterns, the measured values are $-0.0104 \mathrm{~mm} / \mathrm{m}, \quad 0.0495 \mathrm{~mm} / \mathrm{m}$, $0.0487 \mathrm{~mm} / \mathrm{m}$, and $-0.0105 \mathrm{~mm} / \mathrm{m}$, the prediction values are $\quad-0.0096 \mathrm{~mm} / \mathrm{m}, \quad 0.0503 \mathrm{~mm} / \mathrm{m}, \quad 0.05 \mathrm{~mm} / \mathrm{m}$, and $-0.0104 \mathrm{~mm} / \mathrm{m}$, and the difference between the actual and prediction values of EXX is $0.0008 \mathrm{~mm} / \mathrm{m}$. Finally, according to group $\mathrm{C}$, the larger the $X Y$ leveling accuracy difference is, the larger are the percentage errors in kinematic error 
TABLE 5

(a) Validation experiment level parameter list

\begin{tabular}{lcc}
\hline Parameter group & $X$ axis $(\mathrm{mm} / \mathrm{m})$ & $Y$ axis $(\mathrm{mm} / \mathrm{m})$ \\
\hline$A$ & 0.02 & 0.02 \\
$B$ & -0.01 & 0.05 \\
$C$ & 0.05 & -0.005 \\
\hline
\end{tabular}

(b) Validation experiment comparison table

\begin{tabular}{lcccc}
\hline $\begin{array}{l}\text { Parameter } \\
\text { group }\end{array}$ & $\begin{array}{c}\text { Kinematic error } \\
\text { pattern }\end{array}$ & $\begin{array}{c}\text { Actual } \\
\text { value }\end{array}$ & $\begin{array}{c}\text { Prediction } \\
\text { value }\end{array}$ & $\begin{array}{c}\text { Error } \\
\text { value }\end{array}$ \\
\hline \multirow{4}{*}{$A$} & EXX & 0.0205 & 0.0203 & $1 \%$ \\
& EAX & 0.0198 & 0.0202 & $2 \%$ \\
& EYY & 0.0202 & 0.0199 & $1.5 \%$ \\
$B$ & EBY & 0.0195 & 0.0198 & $1.5 \%$ \\
\hline & EXX & -0.0104 & -0.0096 & $8.3 \%$ \\
& EAX & 0.0495 & 0.0503 & $1.6 \%$ \\
& EYY & 0.0487 & 0.05 & $2.6 \%$ \\
& EBY & -0.0105 & -0.0104 & $1 \%$ \\
\hline & EXX & 0.0505 & 0.0503 & $0.4 \%$ \\
& EAX & -0.0055 & -0.0049 & $10.9 \%$ \\
& EYY & -0.0047 & -0.0052 & $9.6 \%$ \\
& EBY & 0.0509 & 0.0499 & $2 \%$ \\
\hline
\end{tabular}

patterns EAX and EYY, which are $10.9 \%$ and $9.6 \%$, respectively, and both are the part of observing leveling $Y$-axis, but the error values are $0.0006 \mathrm{~mm} / \mathrm{m}$ and $0.0005 \mathrm{~mm} / \mathrm{m}$; so, the theoretical value of the prediction model is close to the actual value, and both of them are within $10 \%$, as shown in Table 5.

\section{Conclusions}

This study discussed the machine tool anchor bolt adjustment leveling accuracy and develops a digital level adjustment and measurement module, which can monitor the variation of straightness error instantly. It performed linearity and distortion accuracy measurement and level adjustment path to enhance the machine tool leveling accuracy, solving the error induced by prior manually observed bubble leveling accuracy. The wired measurement was replaced by wireless measurement, and the transmission is stable. Finally, the manual level adjustment time is shortened, and the overall leveling accuracy of machine tool was enhanced. The measurement result was compared with commercially available Wyler level meter. The experimental results are concluded as follows.

(1) This study has surpassed the $0.02 \mathrm{~mm} / \mathrm{m}$ accuracy of prior bubble level. The minimum resolution is increased by at least 10 times, which is as high as $0.0003^{\circ}$, and the $X$ and $Y$ axes level sensors of leveling equipment export 16bit values, which are filtered by Kalman filter. The measured value and the $X$-axis and $Y$-axis are improved by $94.1 \%$ and $86.2 \%$, respectively, after filtering

(2) The stability and repeatability of level detection equipment are analyzed according to the 6Sigma process accuracy (Ca value) and accuracy ( $\mathrm{Cp}$ value) in process capability analysis of the level detection equipment developed in this study. The maximum measurement error is only $0.0003^{\circ}(0.0051 \mathrm{~mm} / \mathrm{m})$, the $\mathrm{Ca}$ value is within grade $\mathrm{A}$ and grade $\mathrm{B}$, and the $\mathrm{Cp}$ value is above grade $\mathrm{A}=2.3$

(3) The experimental results of kinematic error patterns show the maximum error percentage of kinematic error patterns and level values. The maximum error percentage of $X$-axis kinematic error pattern EXX is $4 \%$, the maximum error percentage of $\mathrm{EAX}$ is $9 \%$, the maximum error percentage of $Y$-axis kinematic error pattern EYY is $20 \%$, the maximum error percentage of EBY is $10 \%$, and the EYY has the maximum value. Therefore, the leveling accuracy directly influences the machine tool motion straightness measurement result

(4) According to three groups of experimental results, when the $X Y$ leveling accuracy of regression equation is $0.02 \mathrm{~mm} / \mathrm{m}$, the percentage error is very close to the maximum error percentage which is $2 \%$. When the leveling accuracy is within $(0.05 \mathrm{~mm} / \mathrm{m}$, $-0.005 \mathrm{~mm} / \mathrm{m}$ ), the percentage error is less than $10.9 \%$. Therefore, the regression model is built in human-machine interface, and the maximum error value between actual value and prediction value is $0.0013 \mathrm{~mm} / \mathrm{m}$; meaning, the prediction has best feasibility

(5) Future research will be focused on improving the accuracy level and stability of this level and tilt measurement equipment. Three topics will be followed: first, to observe different firmware filtering, software filtering (PSO, GA, BAS, etc.) and modeling methods to achieve optimization, second, used Ether-CAT or FOCAS2 to connect with CNC controller and immediate compensation technology, and three, this measuring equipment has temperature selfcompensation technology of machine-learning methods, at this time, as the topics also form part of an ongoing study

\section{Data Availability}

The raw/processed data required to reproduce these findings cannot be shared at this time as the data also forms part of an ongoing study.

\section{Disclosure}

All authors have declare that (i) no support, financial or otherwise, has been received from any organization that may have an interest in the submitted work, and (ii) there are 
no other relationships or activities that could appear to have influenced the submitted work.

\section{Conflicts of Interest}

We declare that we have no financial and personal relationships with other people or organizations that can inappropriately influence our work, and there is no professional or other personal interest of any nature or kind in any product, service, and/or company that could be construed as influencing the position presented in, or the review of, the manuscript entitled, "Level Detection Equipment for Measuring the Influence of Different Leveling Accuracies on Linear Error."

\section{References}

[1] D. Benz, T. Botzelmann, H. Kuck, and D. Warkentin, “On low cost inclination sensors made from selectively metallized polymer," Sensors and Actuators A, vol. 123-124, pp. 18-22, 2005.

[2] W. Y. Jywe, C. H. Liu, T. H. Hsu, and C. M. Hsu, Detecting assembly for a multi-axis machine tool, 2010, U.S. Patent No. $7,852,478$.

[3] H. Jung, C. J. Kim, and S. H. Kong, "A MEMS-based electrolytic tilt sensor," in Sensors IEEE, pp. 1199-1202, Daegu, South Korea, 2006.

[4] J. H. Bai, Design of Capacitive Micro-level Using Standard CMOS MEMS Process, National Jinan International University, Master's Thesis, Nantou County, 2010.

[5] J. S. Bajić and D. Z. Stupar, "A simple, low-cost, highsensitivity fiber-optic tilt sensor," Sensors and Actuators A: Physical, vol. 85, pp. 33-38, 2012.

[6] B. Salvador, A. Luque, and J. M. Quero, "Microfluidic capacitive tilt sensor using PCB-MEMS," in IEEE International Conference on Industrial Technology (ICIT), pp. 3356-3360, Seville, Spain, 2015.

[7] X. Zou, P. Thiruvenkatanathan, and A. A. Seshia, "A highresolution micro-electro-mechanical resonant tilt sensor," Sensors and Actuators A: Physical, vol. 220, pp. 168-177, 2014.

[8] C. H. Lee and S. S. Lee, "Study of capacitive tilt sensor with metallic ball," ETRI Journal, vol. 36, no. 3, pp. 361-366, 2014.

[9] P. Yang, T. Takamura, S. Takahashi, and K. Takamasu, "Multiprobe scanning system comprising three laser interferometers and one autocollimator for measuring flat bar mirror profile with nanometer accuracy," Precision Engineering, vol. 35, no. 4, pp. 686-692, 2011.

[10] K. C. Fan, M. J. Chen, and W. M. Huang, "A six-degree-offreedom measurement system for the motion accuracy of linear stages," International Journal of Machine Tools and Manufacture, vol. 38, no. 3, pp. 155-164, 1997.

[11] W. Ptaszynski, A. Gessner, P. Frąckowiak, and R. Staniek, "Straightness measurement of large machine guideways," Metalurgija, vol. 50, no. 4, pp. 281-284, 2011.

[12] International Organization for Standardization, ISO 230-1, Test code for machine tools - Part 1: Geometric accuracy of machines operating under no-load or quasi-static conditions, 2012.

[13] H. T. Asai, S. Tanaka, and K. Uegima, "Fuzzy linear regression analysis with fuzzy model," IEEE Transactions on Systems, Man, and Cybernetics, vol. 12, no. 6, pp. 903-907, 1982.
[14] H. Tanaka and H. Ishibuchi, "Identification of possibilistic linear systems by quadratic membership functions of fuzzy parameters," Fuzzy Sets and Systems, vol. 41, no. 2, pp. 145160,1991

[15] H. Tanaka, H. Ishibuchi, and S. Yoshikawa, "Exponential possibility regression analysis," Fuzzy Sets and Systems, vol. 69, no. 3, pp. 305-318, 1995.

[16] S. Roweis and Z. Ghahramani, "A unifying review of linear Gaussian models," Neural Computation, vol. 11, no. 2, pp. 305-345, 1999.

[17] H. B. Khamseh, S. Ghorbani, and F. Janabi-Sharifi, "Unscented Kalman filter state estimation for manipulating unmanned aerial vehicles," Aerospace Science and Technology, vol. 92, pp. 446-463, 2019.

[18] I. R. Lee, R. L. Hawley, S. Bernsen et al., “A novel tilt sensor for studying ice deformation: application to streaming ice on Jarvis Glacier, Alaska," Journal of Glaciology, vol. 66, no. 255, pp. 74-82, 2020.

[19] S. Łuczak, R. Grepl, and M. Bodnicki, "Selection of MEMS accelerometers for tilt measurements," Journal of Sensors, vol. 2017, Article ID 9796146, 13 pages, 2017.

[20] O. Ozioko, H. Nassar, and R. Dahiya, "3D Printed interdigitated capacitor based tilt sensor," IEEE Sensors Journal, p. 1, 2021.

[21] T. C. Chang and K. J. Wang, "Capability performance analysis for processes with multiple characteristics using accuracy and precision," The Journal of Engineering Manufacture, vol. 228, no. 5, pp. 766-776, 2014.

[22] D. Dimitrov, W. Van Wijck, K. Schreve, N. De Beer, and J. Meljer, "An investigation of the capability profile of the three dimensional printing process with an emphasis on the achievable accuracy," CIRP Annals, vol. 52, no. 1, pp. 189-192, 2010.

[23] National Instruments, Aerospace Science and Technology, vol. 92, pp. 446-463, 2019.

[24] Y. Yang and Y. Deng, "Nonlinear error analysis and experimental measurement of Birefringence-Zeeman dualfrequency laser interferometer," Optics Communications, vol. 436, pp. 264-268, 2019.

[25] Y. Tang and H. Q. Xu, "An effective construction method for multi-level uniform designs," Journal of Statistical Planning and Inference, vol. 43, no. 9, pp. 1583-1589, 2013. 